\title{
Comment on: Reshaping ophthalmology training after COVID-19 pandemic
}

\author{
Merlin Joseph Hetherington ${ }^{1} \cdot$ Obaid Kousha $\mathbb{D}^{1} \cdot{\text { Ahmed Al-Mansour } \text { Ali }^{2} \cdot \text { Fisto Kitema }}^{3} \cdot$ Andrew Blaikie ${ }^{1,2}$
}

Received: 3 August 2020 / Revised: 5 August 2020 / Accepted: 11 August 2020 / Published online: 18 August 2020

(c) The Royal College of Ophthalmologists 2020

\section{To the Editor:}

Ferrara et al. [1] report the dramatic negative effects of the COVID-19 pandemic upon training. Their paper recognises the importance of mitigating these effects by utilising both remote web-based learning and simulation-based surgery. We would like to highlight two additional issues that we feel are important. Firstly, in lower resource settings, remote learning for eye care trainees is often impractical due to students not owning suitable hardware to access material as well as not being able to afford internet access [2]. Secondly, in this era of reduced face-to-face clinical exposure, simulation tools can be used not just for training and maintaining surgical proficiency but also clinical examination skills.

To help overcome these challenges, the University of St Andrews has led the development, evaluation and implementation of a low-cost solar powered ophthalmoscope (Arclight) for trainees in low-resource countries. Studies have shown that compared to a traditional device, the Arclight can be a superior retinal and equally effective red reflex examination tool $[3,4]$ despite its simplified design and low cost [5].

To complement the Arclight, we have also developed and evaluated frugal simulation eyes with modifiable media and a range of printable fundus pathologies (Fig. 1). A 'realism' study comparing the Arclight simulation eyes (ASEs—£18 for a bag of five eyes) with the most widely available device on the market (Adam, Rouilly digital reti- nopathy trainer (AR-DRT)—£1711.20) was performed with 24 third year medical students none of whom had been exposed to the ASE before. After a self-directed hour-long teaching session in which students used both simulators, a seven-point Likert scale and questionnaire was used to acquire feedback.

The students rated the ASE as statistically more 'real' than the AR-DRT in three of the four 'realism' characteristics with 'glare and light reflection' being the same (Fig. 2). A total of $63 \%$ of students preferred the ASE to 'advance their ophthalmoscopy skills' with $31 \%$ favouring the traditional device and $6 \%$ not expressing a preference.

As we reshape training in the COVID-19 era, the Arclight and simulation eyes now raise the realistic prospect of being able to cost-effectively equip trainees with their own personal ophthalmoscope and suite of simulation eyes. This can facilitate remote learning in all regions of the world without the need for expensive hardware or internet access ensuring we still educate the next generation of eye care professionals to address the global burden of blindness.

\section{Compliance with ethical standards}

Conflict of interest $\mathrm{AB}$ is seconded to the University of St Andrews from NHS Fife. The University owns a social enterprise subsidiary company, for which $\mathrm{AB}$ acts as an unpaid adviser. The social enterprise business sells the Arclight ophthalmoscope to users in highresource countries with all profits being used to fund distribution and
Obaid Kousha

ok32@st-andrews.ac.uk

1 Global Health Team, School of Medicine, University of St Andrews, Medical and Biological Sciences Building, North Haugh, St Andrews KY16 9TF, UK
2 Queen Margaret Hospital, NHS Fife, Whitefield Road, Dunfermline KY12 OSU, UK

3 School of Health Sciences, College of Medicine and Health Sciences, University of Rwanda, Kigali, Rwanda 
Fig. 1 Arclight simulation eye (ASE). a Arclight simulation eye constituent parts.

b Fundoscopy appearance.

c Red reflex appearances

(i) leucocoria, (ii) normal and (iii) cataract.
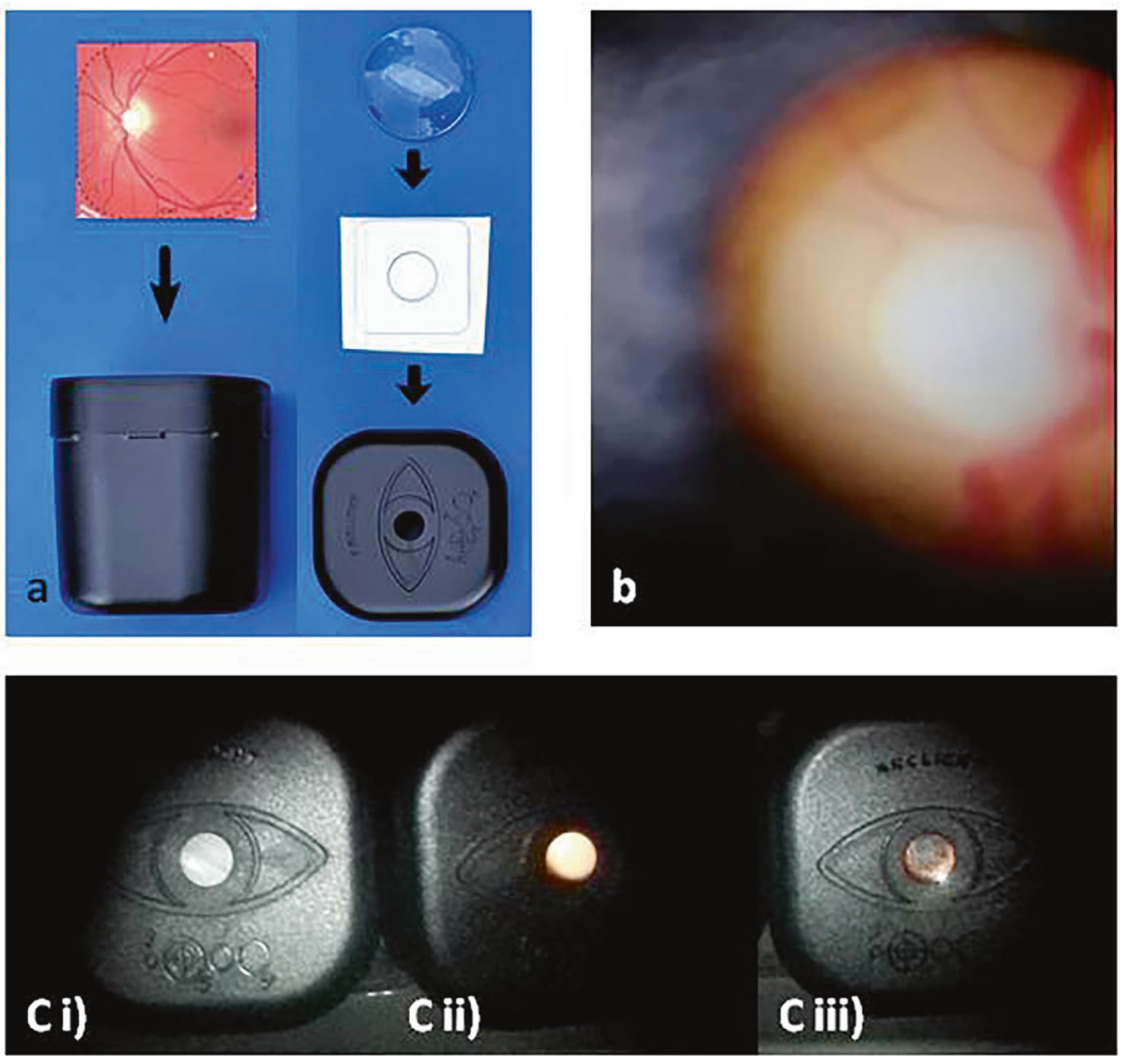

a)

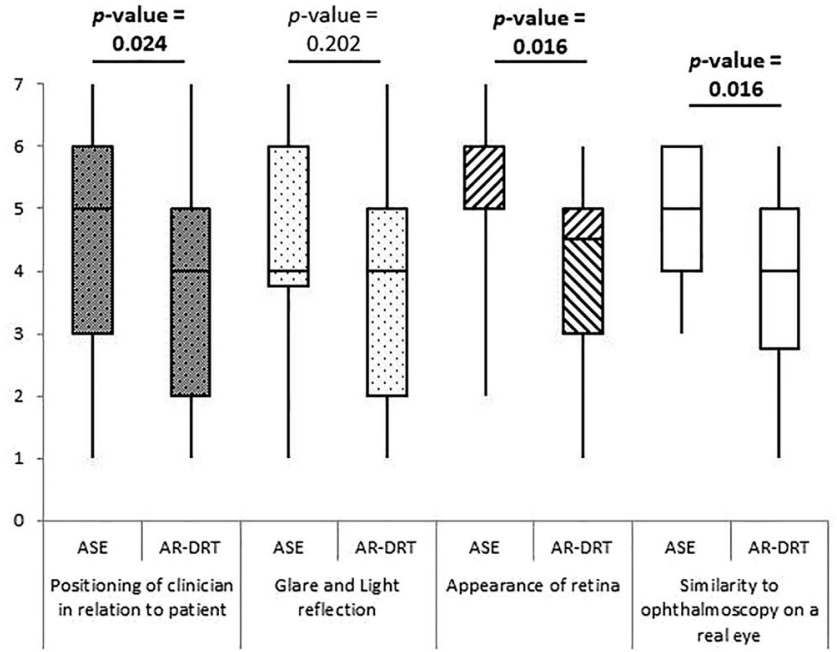

b)

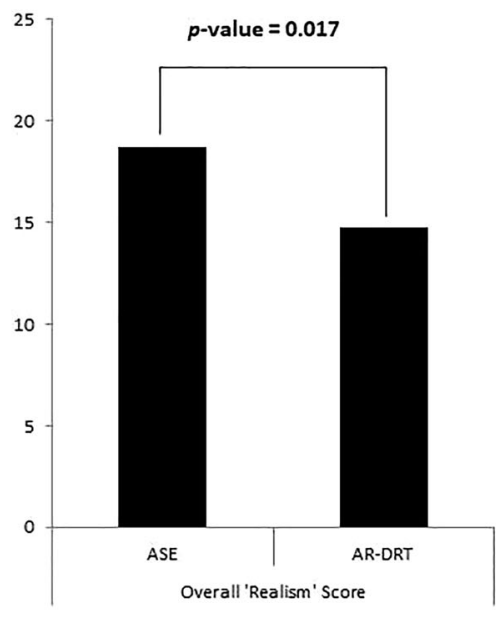

Fig. 2 Comparing Arclight simulation eyes with Adam, Rouilly digital retinopathy trainer. a Box plots comparing the individual and $\mathbf{b}$ the overall "realism" characteristics of the Arclight simulation eyes (ASE) and the Adam,Rouilly digital retinopathy trainer (AR-DRT). The scores were obtained using a seven-point Likert scale.

education exercises of the device in low-income countries via the Global Health Implementation Team at the University of St Andrews. The other authors have no conflict of interest to declare.

Publisher's note Springer Nature remains neutral with regard to jurisdictional claims in published maps and institutional affiliations.

\section{References}

1. Ferrara M, Romano V, Steel DH, Gupta R, Iovino C, van Dijk EHC, et al. Reshaping ophthalmology training after COVID-19 pandemic. Eye. 2020. https://doi.org/10.1038/s41433020-1061-3. 
2. Barteit S, Jahn A, Banda SS, Bärnighausen T, Bowa A, Chileshe G, et al. E-learning for medical education in Sub-Saharan Africa and lowresource settings: viewpoint. J Med Internet Res. 2019;21:e12449.

3. Blundell R, Roberts D, Fioratou E, Abraham C, Msosa J, Chirambo $\mathrm{T}$, et al. Comparative evaluation of a novel solar powered low-cost ophthalmoscope (Arclight) by eye healthcare workers in Malawi. BMJ Innov. 2018;4:98.
4. Dooley E, Kousha O, Msosa J, Ndaule E, Abraham C, Parr J, et al. Comparative evaluation of a low cost direct ophthalmoscope (Arclight) for red reflex assessment among healthcare workers in Malawi. BMJ Innov. 2020;6:113-6.

5. Blaikie A, Sandford-Smith J, Tuteja SY, Williams CD, O'Callaghan C. Arclight: a pocket ophthalmoscope for the 21 st century. BMJ. 2016;355:i6637. 